Review

\title{
Role of Sam68 in Post-Transcriptional Gene Regulation
}

\section{Flora Sánchez-Jiménez and Víctor Sánchez-Margalet *}

Department of Medical Biochemistry and Molecular Biology and Immunology, UGC Clinical Biochemistry, Virgen Macarena University Hospital, Avenue. Sánchez Pizjuan 4, Medical School, University of Seville, Seville 41009; Spain; E-Mail: aerolazure@ gmail.com

* Author to whom correspondence should be addressed; E-Mail: margalet@us.es; Tel.: +34-954-559-850; Fax: +34-954-907-048.

Received: 13 September 2013; in revised form: 11 November 2013 / Accepted: 13 November 2013 / Published: 28 November 2013

\begin{abstract}
The STAR family of proteins links signaling pathways to various aspects of post-transcriptional regulation and processing of RNAs. Sam68 belongs to this class of heteronuclear ribonucleoprotein particle $\mathrm{K}$ (hnRNP K) homology (KH) single domain-containing family of RNA-binding proteins that also contains some domains predicted to bind critical components in signal transduction pathways. In response to phosphorylation and other post-transcriptional modifications, Sam68 has been shown to have the ability to link signal transduction pathways to downstream effects regulating RNA metabolism, including transcription, alternative splicing or RNA transport. In addition to its function as a docking protein in some signaling pathways, this prototypic STAR protein has been identified to have a nuclear localization and to take part in the formation of both nuclear and cytosolic multi-molecular complexes such as Sam68 nuclear bodies and stress granules. Coupling with other proteins and RNA targets, Sam68 may play a role in the regulation of differential expression and mRNA processing and translation according to internal and external signals, thus mediating important physiological functions, such as cell death, proliferation or cell differentiation.
\end{abstract}

Keywords: Sam68; RNA-binding protein; post-transcriptional regulation 


\section{Introduction}

Increasing data has demonstrated that RNA binding proteins (RBP) and ribonucleoproteins (RNP) complexes play multiple roles in regulating a variety of biological processes by the regulation of RNA metabolism [1,2]. An emerging class of proteins participating in RNA homeostasis is represented by the Signal Transduction and Activation of RNA (STAR) family. This family includes the Artemia salina GRP33 [3], the Caenorhabditis elegans GLD-1 and ASD-2 [4], the Drosophila melanogaster HOW [5] and KEP1 [6], the Xenopus Xqua [7], QUAKING (QKI) proteins [8,9], Sam68 [10], Sam like mammalian 1 and 2 (SLM1 or KHDRBS2 and SLM2 or T-STAR, respectively) $[11,12]$ and SF1 $[13,14]$. These evolutionary conserved riboproteins control a wide variety of developmental processes, integrating extracellular signals with changes in transcription and processing of target RNAs.

This family of proteins owes its name and its dual role to the presence of a structural domain for the binding of RNA, the GRP33/SAM68/GLD-1 (GSG) domain of 200 amino acids, flanked by regulatory regions containing motifs for protein-protein interactions and residues that are modified post-translationally [15]. The GSG domain contains a single hnRNP K Homology (KH) domain. KH is an evolutionarily conserved RNA binding domain that consists of 70-100 amino acids, harboring two conserved flanking sequences referred to as $N$ terminus of $\mathrm{KH}$ (NK or Qua1) and $C$ terminus of KH (Qua2) [4]. Two properties have been ascribed to this protein module: RNA-binding affinity to bipartite RNA [16-18] and the ability to homodimerize [6,16]. Moreover, some regions of the STAR proteins suggest their functional role in signal transduction as well. These sequences include proline-rich motifs, arginine glycine-rich regions and tyrosine-rich motifs in the $C$-terminal tail [13].

\section{Sam68 Structure and Posttranscriptional Modifications}

Sam68 (Src-associated in mitosis $68 \mathrm{kDa}$ ), also known as KHDRBS1 (KH domain containing, RNA binding, signal transduction associated 1) is the prototypic member of the STAR family of RNA-binding proteins, which regulate RNA metabolism in response to signaling cascades. Sam68 was the first STAR member to be characterized and was initially described as a cell cycle regulated phosphorylation target of c-Src and cdc2 kinases [19-21]. Moreover, Sam68 amino acid sequence and gene structure defined Sam68 subfamily of STAR proteins, as structurally different from the other two STAR subfamilies: SF1 and Quaking related proteins (reviewed in [13] and [22]).

The KH domain of Sam68 allows the binding of certain RNA sequences with high affinity and specificity. Thus, Sam68 was first shown to bind nonspecifically to poly(U) and poly(A) RNA, and specifically to the high-affinity binding sequences UAAA or UUAA in vitro [17,23]. 3'-UTR (3'-untranslated region) contains an AU-rich sequence, which may be considered a Sam68 target. In addition, Sam68 has been demonstrated to bind some mRNA targets in vivo, including beta-actin mRNA and hnRNP A2/B1 mRNA among others [24]. Other mRNA targets of Sam68 have been recently identified [25], and it remains to be determined whether Sam68 binds a rather undefined site on mRNAs or whether it requires a specific cellular context with other RNA binding proteins. Thus, while the Qua1 domain alone seems to be sufficient for dimerization of the Sam68 STAR domain, the Qua2 domain seems to contribute to the binding to some bipartite target RNAs [26]. Regarding KH 
function, it should be pointed out that a natural spliced variant of Sam68 lacking the KH domain was shown to be specifically expressed under arrested cellular growth, indicating that the KH domain may be necessary for the regulation of G1/S transition during the cell cycle [27].

For its role as a docking protein, Sam68 contains 5 proline-rich motifs which represent binding sites for SH3 and WW domain-containing proteins and a tyrosine rich $C$-term which can be phosphorylated and mediate SH2-dependent interplay with numerous cell signaling components in response to different stimuli [21,23]. In addition, Tyr-phosphorylation produces a negative effect on its RNA binding ability, which may be critical for the linking of extracellular stimuli to RNA processing [28]. Besides tyrosine phosphorylation, serine/threonine phosphorylation of Sam68 takes place through eight potential proline-directed MAPK phosphorylation sites [29,30]. Other posttranslational modifications have been described for Sam68: acetylation of lysine residues within the GSG domain by histone acetyltransferases positively regulates RNA binding [31], and methylation of RG (arginine/glycine)-rich regions by arginine $N$-methyltransferases is required for RNA export inducing localization to the nuclear compartment [32,33]. Also, SUMOylation (binding of a small ubiquitin-related modifier) has been described to modify Sam68 functionality by repressing the expression of cyclin D1 and resulting in G1 arrest and inhibition of cell proliferation [34].

\section{Role of Sam68 in Signaling}

Despite its predominantly nuclear localization determined by a nuclear localization signal (NLS) in the $C$-terminus [35], Sam68 was first identified as the major phosphorylation substrate for Src in the cytoplasm during mitosis [21]. In this context, not only the subcellular localization of Sam68, but also its function and affinity for RNA are strongly modulated by several signaling pathways.

Sam68 has been found to bind the SH3 domains of p85 phosphatidylinositol 3-kinase (PI3K) [19], phospholipase C gamma-1 (PLC $\gamma-1)$ [23,36], protein arginine methyltransferase (PRMT) [32], Grb-2 [37], Grap [38] and Nck [39] through these polyproline motifs. Sam68 is also a target of MAPKs (via Ser/Thr phosphorylation) like Erk1/2 or Erk5 $[29,40]$ and several tyrosine kinases such as Src, Fyn, Lck, Tec, Jak3, Brk, Zap70, Btk or the insulin receptor [41-45]. Tyrosine-phosphorylated Sam68 allows its association with numerous SH2 domain containing proteins including Src family kinases [10,21,23], Sik/BRK [41], PLC $\gamma$-1 [10], RasGAP [46,47] and Itk/Tec family kinases [48]. More recently, Sam68 has been studied to directly interact with TNFR1 (TNF-alpha receptor 1) and RIPK1 (receptor interacting protein kinase1) and also with FADD in the caspase-8/FADD/RIPK1 complex [49].

Thus, Sam68 acts as a scaffold protein in response to activation of membrane-bound receptors and extracellular signaling pathways, such as the T-cell receptor [43,48,50-52], insulin receptor [45,53], leptin receptor [54-57], TNF-alpha [58], EGF [59] or HGF/Met signaling [60]. As happens with other RBPs, the interplay between kinases, Sam68 and target RNAs have been suggested in the dynamic regulation of gene expression according to cell signaling. More precisely, a recent work has defined RNA-binding proteins, including Sam68, as a point of convergence of the PI3K and p38MAPK pathways [61]. Accordingly, Sam68 has been proposed to be a mediator of biological effects of some extracellular signals. Sam68 Tyr-phosphorylation, its negative effects on RNA binding and its participation on signaling pathways might play a key role on cellular events, such as proliferation or 
cell growth $[62,63]$ providing a rapid pathway for regulating protein expression by modifying mRNA stability, processing or translation.

Regarding the biological function of Sam68, it has been considered both as a tumor suppressor and a proto-oncogene regulating cell cycle progression and apoptosis through both RNA dependent and RNA-independent mechanisms [20,27,34,64-66]. Sam68 expression level and phosphorylation status in response to extracellular stimuli play a role in tumorigenesis as well. For example, phosphorylation of the Sam68 $C$-terminal domain at Tyr440 by Breast cancer kinase (Brk) has been reported to direct Sam68 to nuclear localization and cell cycle progression [59]. Moreover, tyrosine phosphorylation of Sam68 has been shown to be elevated in human breast and prostate tumor tissues and cell lines $[31,59,67]$, contributing to the growth, proliferation, and invasion of these cancer cells [60,68-73].

Further insights of Sam68 function and physiologic role have been provided by studying Sam68 haploinsufficiency. Even though most $\mathrm{Sam}_{68^{-/-}}$mice have shown normal life span and development [74], some interesting effects have been described on mice in relation to impaired fertility [75,76], delayed onset of mammary tumorigenesis and metastasis [69], basal motor coordination failure [77], maintenance of bone mass with aging [74] or protection from obesity, insulin resistance, and glucose intolerance induced with a high-fat diet by inhibiting adipogenesis [78]. These insights have also pointed out the possible role of Sam68 as a modulator of the RNA processing of some key proteins involved in signal transduction pathways, where Sam68 might have a direct participation through protein-protein interactions and posttranscriptional modifications.

\section{Sam68 in RBP Complexes}

In addition to the docking role of Sam68 in cytosolic cell signaling, Sam68 has been described to take part in some ribonucleoprotein complexes. Various other RNPs and proteins were found to be directly associated to Sam68 in the nucleus. For example, the binding to hnRNP K was described to cause antagonistic effect to their respective transcriptional activities [79]. Sam68 association to other nuclear proteins, such as hnRNP A1 [80], hnRNP G [12,81] or FAST [82] has also been described, suggesting the participation of Sam68 in pre-mRNA processing. Recently, neurological defects have been associated with alterations in hnRNPs, such as hnRNP A1 mutations, which produce familial amyotrophic lateral sclerosis [83]. Moreover, lower expression of hnRNP A/B has been found in mice models of Alzheimer disease, mediating alternative missplicing [84]. Even though Sam68 may interact with these hnRNPs, the possible role of Sam68 in these neurological alterations remains to be studied.

In cancer cells, apart from Sam68 protein showing a general nucleoplasmic distribution, Sam68 has been found to be also concentrated within subnuclear organelles called SLM/Sam68 Nuclear Bodies (SNBs), which also contain some other splicing regulators, signaling components and nucleic acids [85]. These nuclear structures show dynamic changes in response to transcriptional inhibitors, growth factors like EGF [86] and during mitosis, depending on ongoing RNA polymerase II transcription, even when these nuclear bodies do not appear to concentrate newly synthesized RNAs. Brk (PTK6), a kinase similar to c-Src, which is phosphorylated and activated by growth factor receptor signaling, was shown to colocalize with Sam68 in these dynamic spherical nuclear structures [85]. Also, Sam68-like mammalian proteins (SLM-1 and SLM-2), the heterogeneous nuclear ribonucleoproteins hnRNP A2/B1 and hnRNP G, the splicing factor YT521 [87], Sik/BRK [41] and more recently, 
the splicing repressor hnRNP L [88], have been described to interact with Sam68 in SNBs, thus suggesting a role for these organelles in coupling signaling to RNA processing in cancer cells.

Some cellular stresses, such as UV light, chemical insults or hyper-osmotic condition, as well as heat shock stress can induce accumulation of several RBPs in nuclear stress bodies [89]. This is a mechanism that cells adopt to limit and overcome the damage through cell cycle arrest and DNA repair. SAF-B/HAP scaffold attachment factor-B (hnRNP A1 interacting protein), ASF/SF2 and Sam68 are recruited in long tandem arrays of Satellite III (SatIII) DNA [90]. These RNP complexes are considered stress related SNBs and include other pre-mRNA processing factors that were shown to have a role in cellular response to heat shock stress [91]. Thus, these transcriptionally active granules, where Sam68 is accumulated in addition to other splicing factors, have been suggested to alter the cellular alternative splicing pattern in response to genotoxic insults, as it has been shown in tumoral cells in response to some drugs [92].

A number of different cellular structures have been demonstrated to include Sam68 in cytoplasmic localization. For instance, some other stress granules (SG), such as cytoplasmic foci, appear in cells exposed to various environmental stress agents. They are mainly composed of non-functional translation pre-initiation complexes that aggregate after phosphorylation of the alpha subunit of eukaryotic translation initiation factor 2 (eIF2 $\alpha$ ) in response to oxidative stress, hypoxia, UV exposure or heat shock [93]. Particularly, in response to oxidative stress, Sam68 was found to be recruited to SG and complexed with T-cell intracellular antigen (TIA-1), a core SG component [94], and with Ras-Gap binding protein-1 (G3BP1) [86]. The formation of viral SG in poliovirus [95] and herpes simplex virus infection [96] has been related to Sam68 as well, demonstrating the role of Sam68 in cellular responses to some viral infections. In addition, Sam68 has been reported to transiently localize in the chromatoid bodies (CB) during meiotic divisions and in early post-meiotic cells, suggesting a novel role for Sam68 in CB-linked RNA processing events and in the miRNA pathway during spermatogenesis [97].

\section{Sam68 and Alternative Splicing}

Alternative splicing (AS) is a major cause of mRNA variability and protein diversity in eukaryotes. Some sequences of RNA in the splice site or its vicinity interact with proteins that can be subdivided into SR proteins and hnRNPs [1], recruiting components of general splicing machinery or blocking this recruitment respectively. Alternative splicing is regulated in part by a network of signaling pathways which respond to extracellular stimuli [98].

Due to the binding of the splicing factor YT521-B to SAF-B to regulate the selection of alternative splice sites, and the evidence of Sam68 binding to YT521-B, Sam68 was suggested, for the first time, to be part of a signal transduction pathway that can influence splice site selection [87]. There is more evidence supporting this hypothesis, such as the described Sam68 binding to intronic regulatory pre-mRNAs [99], the binding of Sam68 to spliceosome-associated proteins [33] or to some splicing factors [12].

The molecular mechanism through which Sam68 regulates AS decisions in response to signaling cascades is poorly understood. All Sam68 and Sam68-like mammalian proteins have been implicated in alternative splicing of target pre-mRNAs [29,80,100]. Tyrosine phosphorylation of these splicing regulatory proteins seems to change splice site selection, as it was studied for p59fyn-mediated 
phosphorylation of SLM-1 [101]. However, insights into the biological function of these processes have only been obtained for Sam68 so far. Moreover, the role of Sam68 participating in alternative splicing has been demonstrated to be related to tumorigenesis and important cellular decisions such as cell survival or cell death [80]. Specifically, Sam68 has been shown to be frequently upregulated in some tumors, like breast cancer [102], prostate [68,103], oral tongue [72], cervical cancer [71], renal carcinoma [104] and more recently, colorectal cancer [73]. In many of them, a role for Sam68 in RNA processing and AS has been suggested.

Signaling pathways attributed to growth factors receptor activation, such as ERK1/2 pathway, seem to modulate alternative splicing through Sam68 phosphorylation, promoting some tumoral effects. CD44 encodes a cell surface molecule involved in cell adhesion, proliferation, and migration of cancer cells [105]. Ras-pathway-stimulated splicing of one variant of CD44 exons (inclusion of exon v5, which is frequent during tumor progression) in mouse T-lymphoma cells seems to be regulated by Sam68. This protein was shown to bind to sequences within the v5 exon and to be phosphorylated by ERK MAP-kinase at several sites upon Ras pathway activation [29]. Subsequent studies have shown that Sam68 cooperates with proteins that promote the inclusion of the v5 exon of CD44 alternative splicing, such as the splicing activator SRm160 [106], the chromatin remodeling protein Brm, which seems to be required for the binding of Sam68 to the RNAPII (RNA polymerase II) [107], or more recently, SND1, which also recruits Sam68 together with other factors to the pre-mRNA of CD44 in prostate cancer cells [108]. The binding of Sam68 to Brm was hypothesized to slow down the rate of RNAPII on genes regulated by the chromatin remodeling complex, thus facilitating recruitment of the splicing machinery to specific splice sites [107]. Moreover, Sam68 and Brm seem to be necessary for the alternative splicing of the human papillomavirus (HPV) polycistronic pre-mRNA, also dependent on EGF-mediated Erk1/2 activation [109]. In addition, other mechanisms have been suggested regarding how the signal-dependent modification of the Sam68 protein can affect the splicing machinery. As part of the key step in spliceosome formation, the pre-mRNA occupancy of U2AF (U2 snRNP auxiliary factor) has been shown to be downregulated by ERK-dependent Sam68 phosphorylation in vivo, which affects the splice site occupancy of its binding partner U2AF65 as a step to control spliceosome assembly at regulated splice sites [110].

In addition to Sam68 participation in CD44 alternative splicing correlating with enhanced malignancy and invasiveness of some tumors, this protein has been related to some other effects promoting tumorigenesis and proliferation through AS regulation. Thus, in response to extracellular stimuli, Sam68 was found to regulate the alternative splicing of the SR protein splicing factor and proto-oncogene SF2/ASF through the nonsense-mediated mRNA decay pathway (AS-NMD). Through SF2/ASF AS regulation, Sam68 has also been shown to play a role in the epithelial-to mesenchymal transition during tumor metastasis [111]. Other reported effects of Sam68 on AS in tumoral cells include the modulation of androgen receptor-dependent alternative splicing in prostate cancer LNCaP cells [103]. In these cells, also Sam68 binding to Cyclin D1 mRNA has been shown to favour the splicing of the D1b variant, which is associated with increased prostate cancer risk [112].

Moreover, Sam68 has also been shown to play a role in the regulation of Bcl-x alternative splicing in cooperation with hnRNP A1 in HEK293 cells [80]. Even though upregulation of Sam68 increases the levels of proapoptotic Bcl-x short isoform (S), Fyn-dependent Sam68 Tyr-phosphorylation seems to switch its role from proapoptotic to antiapoptotic, favoring the Bcl-x long isoform (L) splice site 
selection [80]. Alternatively, a similar effect was shown when the Fyn-HnRNP A2B1/Sam68-signaling pathway activation was found to reduce the proapoptotic $\mathrm{Bcl}-\mathrm{x}(\mathrm{S})$ isoform in pancreatic cells [42]. Therefore, in addition to ERK dependent phosphorylation of Sam68, Tyr-phosphorylation was demonstrated to have a role in Sam68 modulating AS, as it was mechanistically shown by Sam68 binding to APC-arm in colorectal tumors [113]. The modulation of Sam68's role in splicing may explain why that in cancer cells, Sam68 is distributed in the cytoplasm instead of the nucleus and is highly phosphorylated in response to some trophic and mitogenic signals [45,57]. This may lead to a differential regulation of Bcl-x splicing and combined with some other effects, may promote proliferation and metastasis.

There is in addition, mounting evidence that indicates a role of Sam68 in the regulation of alternative splicing during cellular differentiation in different tissues, namely in spermatogenesis, neurogenesis and adipogenesis.

In spermatogenesis, it has been suggested that Sam68 regulates alternative splicing at transcriptionally active sites in differentiating germ cells. Sam68 interacts with the phosphorylated form of the RNA polymerase II (RNAPII) and binds to transcriptionally active chromatin in pachytene spermatocytes, where it seems to modulate alternative splicing of mRNA targets in male germ cells, such as murine Sgce [100,114].

The participation of Sam68 in alternative splicing has been demonstrated also in neurogenesis, where Sam68 seems to regulate the splicing of specific pre-mRNAs, which are important for neural development [100,115]. Moreover, Sam68 has also been shown to be a key regulator of activity dependent alternative splicing in the central nervous system [116]. Besides, the splicing activity of Sam68 has recently been implicated in the onset of two human neurodegenerative diseases. Thus, recent studies have found Sam68 colocalized with MBNL1 (muscle blind-like), and hnRPN G proteins within CGG mRNA aggregates, which are supposed to play a role in the regulation of AS in Fragile X-associated tremor/ataxia syndrome (FXTAS). This neurodegenerative disorder is due to an RNA gain-of-function mechanism, where RNA toxicity due to the elevated FMR1 mRNA levels is observed in premutation carriers. Sam68 is sequestered by expanded CGG repeats and thereby loses its splicing-regulatory function whereas Sam68 Tyr-phosphorylation seems to reduce its recruitment [117]. In the neurodegenerative disorder spinal muscular atrophy (SMA), Sam68 has been shown to be a novel and crucial regulator of SMN2 alternative splicing, acting as a splicing repressor of exon 7 inclusion through both its cooperation with hnRNP A1 and its RNA binding ability [118,119].

More recently, Sam68 has been reported to regulate alternative splicing of the PI3K downstream effector mTOR in adipogenesis. Sam68 deficiency resulted in mTOR intron 5-retention through the introduction of a premature termination codon and the subsequent reduction of protein levels of mTOR [78]. Thus, Sam68 activation and participation in the PI3K pathway, as previously reported [45,62], may also mediate the regulation of the abundance of PI3K downstream kinases, such as mTOR. Along these lines, other studies have linked RNA-binding proteins participation in PI3K and MAPK signaling pathways by phosphorylation [61]. 


\section{Other Sam68 Functions in RNA Metabolism: Transcription, Translation, miRNA Processing and RNA Transport}

Sam68 could also have a role in transcriptional regulation and may behave as a competitive inhibitor of positive regulators of transcription, as has been shown by repressing various mammalian and viral promoter constructs. Thus, binding of Sam68 to hnRNP K inhibits the function of hnRNP K in transcriptional activation of a reporter driven by the CT promoter element of the proto-oncogene c-myc [79]. Most of these functions of Sam68 regulating transcription are mediated by protein-protein interaction, as previously shown with the inhibition of the transcriptional activity of the multifunctional adaptor CBP [120]. In this context, there is increasing evidence for the concept of spatial and temporal coupling between splicing and transcription, especially with nuclear factors [121]. Sam68 also directly interacts with the androgen receptor and binds to androgen responsive elements (AREs) within the promoter region of the prostate-specific antigen (PSA) gene, where Sam68 seems to have some effect on AR-regulated transcriptional activity independently of its ARN binding capacity and splicing regulatory properties in LNcaP cells [103]. Sam68 may also be acting as a co-activator of ER-dependent transcription in mammary development and tumorigenesis [69]. Moreover, Sam68 is required to guarantee proper expression of the gonadotropin receptor transcripts in pre-ovulatory follicles from adult ovary with a possible role upregulating both the FSH and LH receptor transcripts [75].

In addition to transcriptional and posttranscriptional functions of Sam68, increasing evidence has shown that Sam68 could also play a role in translation [122]. In male germ cells Sam68 is mainly nuclear, but it translocates into the cytoplasm of secondary spermatocytes, where it regulates the translation of specific mRNA targets in association with polysomes [30,76]. In secondary spermatocytes and early round spermatids, Sam68 has been shown to interact with the translational machinery, associating to eIF4F in an effect that seems to be strongly correlated with ERK-dependent Sam68 phosphorylation [76].

Recent studies have also proposed a role for Sam68 in the miRNA pathway during its translocation and accumulation in chromatoid bodies in spermatogenesis [97]. Based on previously known Sam68 interaction with DROSHA and DICER, the two RNase III enzymes involved in the nuclear and cytoplasmic processing of the miRNA precursors [123], twelve miRNAs were differentially shown to be expressed between wild-type and knockout Sam $68^{-/}$germ cells. These miRNAs included miR-29b, which belongs to a family of miRNAs that are often down-regulated in human cancers [124]. Thus, increased expression of Sam68 in some cancer cells, such as prostate cancer, may be required to suppress miR-29b expression and promote an aggressive phenotype [111,125].

Most of the evidence regarding the role of Sam68 in RNA export has been based on studies of retroviral mRNA processing [126]. The human immunodeficiency virus (HIV-1) differentially controls viral protein expression at the level of splicing as well as nuclear export of incompletely spliced viral RNA, mediated by Rev protein. Sam68 was initially found to bind to Rev and synergize not only CRM1-dependent RNA transport but also RRE-mediated gene expression and viral replication of HIV-1 [127,128]. Direct evidence of the essential role of Sam68 in nuclear export of RRE-containing RNA and Rev function was shown by reducing Sam68 expression, which caused dramatic inhibition of HIV-1 production [129]. Also, Sam68 tyrosine phosphorylation was observed to impair Sam68 ability to facilitate the export of unspliced RNAs [41]. In other contexts, Sam68 may 
promote the transport and association of mRNAs to specific cellular localizations. Recently, Sam68 has been shown to promote the association of Beta-actin mRNA with synaptic polyribosomes specifically in the synaptodendritic compartment, thus regulating hippocampal synapse number [130].

Table 1. Sam68 participation in different diseases.

\begin{tabular}{|c|c|c|c|c|}
\hline Disease & Effect & Role of Sam68 & Suggested mechanism & Ref. \\
\hline $\begin{array}{l}\text { Fragile X-associated } \\
\text { tremor/ataxia syndrome } \\
\text { (FXTAS) }\end{array}$ & Clinical disease & Regulation of alternative splicing & CGG repeats recruit Sam68 & {$[117]$} \\
\hline $\begin{array}{l}\text { Spinal muscular atrophy } \\
\text { (SMA) }\end{array}$ & Clinical disease & $\begin{array}{l}\text { Regulation of } \\
\text { alternative splicing }\end{array}$ & $\begin{array}{l}\text { Sam68 is repressor of exon } 7 \\
\text { inclusion of SMN2 }\end{array}$ & [118] \\
\hline Breast cancer & $\begin{array}{l}\text { Tumor progression, } \\
\text { tumorigenesis, } \\
\text { metastasis }\end{array}$ & $\begin{array}{l}\text {-Sam68 overexpression and } \\
\text { cytoplasmic localization } \\
\text {-Sam68 haploinsuficiency delays } \\
\text { onset of mammary tumorigenesis } \\
\text { and metastasis }\end{array}$ & $\begin{array}{l}\text {-Complex formation } \\
\text { (Brk, ERK5, Sam68) under } \\
\text { MET receptor activation } \\
\text {-Cell cycle regulation } \\
\text {-Sam68 modulation of Tyr } \\
\text { kinase activity }\end{array}$ & $\begin{array}{l}{[60]} \\
\\
{[102]} \\
{[69]}\end{array}$ \\
\hline Prostatic cancer & $\begin{array}{l}\text { Neoplasmic } \\
\text { transformation of } \\
\text { prostatic cells }\end{array}$ & $\begin{array}{l}\text {-Src depending Sam68 } \\
\text { phosphorylation } \\
\text {-Sam68 overexpression }\end{array}$ & $\begin{array}{l}\text {-Nonregulated Sam68 } \\
\text { phosphorylation may alter } \\
\text { truncated c-kit expression } \\
\text {-Cell cycle regulation } \\
\end{array}$ & $\begin{array}{l}{[67]} \\
{[68]} \\
\end{array}$ \\
\hline Colorectal cancer & Tumor progression & $\begin{array}{l}\text { Sam68 overexpression and nuclear } \\
\text { localization }\end{array}$ & Unknown & [73] \\
\hline Cervical cancer & Tumor progression & $\begin{array}{l}\text { Sam68 overexpression and } \\
\text { cytoplasmic localization }\end{array}$ & $\begin{array}{l}\text { Regulation of epithelial/ } \\
\text { mesenquimal transition }\end{array}$ & [71] \\
\hline Renal cell carcinoma & Tumor progression & $\begin{array}{l}\text { Sam68 overexpression and } \\
\text { cytoplasmic localization }\end{array}$ & Unknown & [104] \\
\hline N0 oral tongue cancer & Tumor progression & $\begin{array}{l}\text { Sam68 overexpression and } \\
\text { cytoplasmic localization }\end{array}$ & Unknown & {$[72]$} \\
\hline Infertility/Subfertility & $\begin{array}{l}\text { Alteration of ovary } \\
\text { function and } \\
\text { spermatogenesis } \\
\text { defects }\end{array}$ & $\begin{array}{l}\text {-Disregulation of RNA metabolism } \\
\text { in Sam } 68 \text { knockout mice } \\
\text {-Regulation of protein translation }\end{array}$ & $\begin{array}{l}\text {-Binding/downregulation of } \\
\text { FSH and LH receptors mRNAs } \\
\text {-Interaction with translational } \\
\text { machinery in polysomes. }\end{array}$ & $\begin{array}{l}{[75]} \\
{[76]}\end{array}$ \\
\hline
\end{tabular}

\section{Conclusions}

Sam68 has been suggested to participate in a variety of biological processes regarding its apparent multifunctionality as a prototypic member of STAR family of proteins. Sam68 structure justifies its docking function in signaling, where $\mathrm{SH} 3$ and $\mathrm{SH} 2$ interactions, in addition to Sam68 phosphorylation, mediate signal transduction of extracellular stimuli.

Sam68 posttranscriptional modifications, its association to other proteins and RNA targets seem to account for both Sam68 function and its intracellular dynamics. Thus, Sam68 shows different biological functions depending on the signaling status of the cell, which may mediate a role of Sam68 in transcriptional processes, posttranscriptional events, such as alternative splicing, regulation of miRNA pathway, translation, or RNA transport. Nevertheless, further studies are needed to understand the specific role of Sam68 integrating the broad variety and complexity of external and internal signals in relation to its participation in multi-molecular complexes and the modulation of key steps of RNA 
processing. More precisely, a better knowledge of the contextual interaction of many proteins and RNA molecules that may associate with Sam68 is needed. Moreover, further studies investigating the biological effects of Sam68 downregulation or knockout may be useful to clarify the role of Sam68 in the processing of specific RNA targets and how it may affect biological processes. Finally, regarding Sam68 biological functions and its implication in some pathophysiological conditions (see Table 1), further studies combining basic and clinical approaches may be necessary to confirm the relevance of Sam68, as well as to define its putative use, both as a molecular marker and as a molecular target, for the development of new therapies.

\section{Acknowledgments}

Research was supported through the Instituto de Salud Carlos III (ISCIII), Grants PS09/00119 and PS12/00117.

\section{Conflicts of Interest}

The authors declare no conflict of interest.

\section{References}

1. Dreyfuss, G.; Kim, V.N.; Kataoka, N. Messenger-RNA-binding proteins and the messages they carry. Nat. Rev. Mol. Cell Biol. 2002, 3, 195-205.

2. Wang, D.; Liang, X.; Chen, X.; Guo, J. Ribonucleoprotein complexes that control circadian clocks. Int. J. Mol. Sci. 2013, 14, 9018-9036.

3. Cruz-Alvarez, M.; Pellicer, A. Cloning of a full-length complementary DNA for an artemia salina glycine-rich protein. Structural relationship with RNA binding proteins. J. Biol. Chem. 1987, 262, 13377-13380.

4. Jones, A.R.; Schedl, T. Mutations in gld-1, a female germ cell-specific tumor suppressor gene in caenorhabditis elegans, affect a conserved domain also found in Src-associated protein Sam68. Genes Dev. 1995, 9, 1491-1504.

5. Baehrecke, E.H. Who encodes a KH RNA binding protein that functions in muscle development. Development 1997, 124, 1323-1332.

6. Di Fruscio, M.; Chen, T.; Bonyadi, S.; Lasko, P.; Richard, S. The identification of two drosophila $K$ homology domain proteins. KEP1 and SAM are members of the Sam68 family of GSG domain proteins. J. Biol. Chem. 1998, 273, 30122-30130.

7. Zorn, A.M.; Krieg, P.A. The KH domain protein encoded by quaking functions as a dimer and is essential for notochord development in xenopus embryos. Genes Dev. 1997, 11, 2176-2190.

8. Ebersole, T.A.; Chen, Q.; Justice, M.J.; Artzt, K. The quaking gene product necessary in embryogenesis and myelination combines features of RNA binding and signal transduction proteins. Nat. Genet. 1996, 12, 260-265.

9. Mezquita, J.; Pau, M.; Mezquita, C. Four isoforms of the signal-transduction and RNA-binding protein QKI expressed during chicken spermatogenesis. Mol. Reprod. Dev. 1998, 50, 70-78. 
10. Richard, S.; Yu, D.; Blumer, K.J.; Hausladen, D.; Olszowy, M.W.; Connelly, P.A.; Shaw, A.S. Association of p62, a multifunctional SH2- and SH3-domain-binding protein, with src family tyrosine kinases, Grb2, and phospholipase C Gamma-1. Mol. Cell. Biol. 1995, 15, 186-197.

11. Di Fruscio, M.; Chen, T.; Richard, S. Characterization of Sam68-Like mammalian proteins SLM-1 and SLM-2: SLM-1 is a Src substrate during mitosis. Proc. Natl. Acad. Sci. USA 1999, 96, 2710-2715.

12. Venables, J.P.; Vernet, C.; Chew, S.L.; Elliott, D.J.; Cowmeadow, R.B.; Wu, J.; Cooke, H.J.; Artzt, K.; Eperon, I.C. T-STAR/ETOILE: A novel relative of SAM68 that interacts with an RNA-binding protein implicated in spermatogenesis. Hum. Mol. Genet. 1999, 8, 959-969.

13. Vernet, C.; Artzt, K. STAR, a gene family involved in signal transduction and activation of RNA. Trends Genet. 1997, 13, 479-484.

14. Arning, S.; Gruter, P.; Bilbe, G.; Kramer, A. Mammalian splicing factor SF1 is encoded by variant cDNAs and binds to RNA. RNA 1996, 2, 794-810.

15. Burd, C.G.; Dreyfuss, G. Conserved structures and diversity of functions of RNA-binding proteins. Science 1994, 265, 615-621.

16. Chen, T.; Damaj, B.B.; Herrera, C.; Lasko, P.; Richard, S. Self-association of the single-KH-domain family members Sam68, GRP33, GLD-1, and Qk1: Role of the KH domain. Mol. Cell. Biol. 1997, 17, 5707-5718.

17. Lin, Q.; Taylor, S.J.; Shalloway, D. Specificity and determinants of Sam68 RNA binding. Implications for the biological function of K homology domains. J. Biol. Chem. 1997, 272, 27274-27280.

18. Galarneau, A.; Richard, S. The STAR RNA binding proteins GLD-1, QKI, SAM68 and SLM-2 bind bipartite RNA motifs. BMC Mol. Biol. 2009, 10, 47.

19. Taylor, S.J.; Anafi, M.; Pawson, T.; Shalloway, D. Functional interaction between c-Src and its mitotic target, Sam 68. J. Biol. Chem. 1995, 270, 10120-10124.

20. Resnick, R.J.; Taylor, S.J.; Lin, Q.; Shalloway, D. Phosphorylation of the Src substrate Sam68 by Cdc2 during mitosis. Oncogene 1997, 15, 1247-1253.

21. Fumagalli, S.; Totty, N.F.; Hsuan, J.J.; Courtneidge, S.A. A target for Src in mitosis. Nature 1994, 368, 871-874.

22. Lukong, K.E.; Richard, S. Sam68, the KH domain-containing superSTAR. Biochim. Biophys. Acta 2003, 1653, 73-86.

23. Taylor, S.J.; Shalloway, D. An RNA-binding protein associated with Src through its SH2 and SH3 domains in mitosis. Nature 1994, 368, 867-871.

24. Itoh, M.; Haga, I.; Li, Q.H.; Fujisawa, J. Identification of cellular mRNA targets for RNA-binding protein Sam68. Nucleic Acids Res. 2002, 30, 5452-5464.

25. Tremblay, G.A.; Richard, S. MRNAs associated with the Sam68 RNA binding protein. RNA Biol. 2006, 3, 90-93.

26. Meyer, N.H.; Tripsianes, K.; Vincendeau, M.; Madl, T.; Kateb, F.; Brack-Werner, R.; Sattler, M. Structural basis for homodimerization of the Src-associated during mitosis, 68-kDa protein (Sam68) qua1 domain. J. Biol. Chem. 2010, 285, 28893-28901. 
27. Barlat, I.; Maurier, F.; Duchesne, M.; Guitard, E.; Tocque, B.; Schweighoffer, F. A role for Sam68 in cell cycle progression antagonized by a spliced variant within the KH domain. J. Biol. Chem. 1997, 272, 3129-3132.

28. Wang, L.L.; Richard, S.; Shaw, A.S. P62 Association with RNA is regulated by tyrosine phosphorylation. J. Biol. Chem. 1995, 270, 2010-2013.

29. Matter, N.; Herrlich, P.; Konig, H. Signal-dependent regulation of splicing via phosphorylation of Sam68. Nature 2002, 420, 691-695.

30. Paronetto, M.P.; Zalfa, F.; Botti, F.; Geremia, R.; Bagni, C.; Sette, C. The nuclear RNA-binding protein Sam68 translocates to the cytoplasm and associates with the polysomes in mouse spermatocytes. Mol. Biol. Cell 2006, 17, 14-24.

31. Babic, I.; Jakymiw, A.; Fujita, D.J. The RNA binding protein Sam68 is acetylated in tumor cell lines, and its acetylation correlates with enhanced RNA binding activity. Oncogene 2004, 23, 3781-3789.

32. Cote, J.; Boisvert, F.M.; Boulanger, M.C.; Bedford, M.T.; Richard, S. Sam68 RNA binding protein is an in vivo substrate for protein arginine $N$-methyltransferase 1. Mol. Biol. Cell 2003, 14, 274-287.

33. Bedford, M.T.; Frankel, A.; Yaffe, M.B.; Clarke, S.; Leder, P.; Richard, S. Arginine methylation inhibits the binding of proline-rich ligands to Src homology 3, but not WW, domains. J. Biol. Chem. 2000, 275, 16030-16036.

34. Babic, I.; Cherry, E.; Fujita, D.J. SUMO modification of Sam68 enhances its ability to repress cyclin D1 expression and inhibits its ability to induce apoptosis. Oncogene 2006, 25, 4955-4964.

35. Ishidate, T.; Yoshihara, S.; Kawasaki, Y.; Roy, B.C.; Toyoshima, K.; Akiyama, T. Identification of a novel nuclear localization signal in Sam68. FEBS Lett. 1997, 409, 237-241.

36. Maa, M.C.; Leu, T.H.; Trandel, B.J.; Chang, J.H.; Parsons, S.J. A Protein that is highly related to GTPase-activating protein-associated p62 complexes with phospholipase C gamma. Mol. Cell. Biol. 1994, 14, 5466-5473.

37. Najib, S.; Sanchez-Margalet, V. Sam68 associates with the SH3 domains of Grb2 recruiting GAP to the Grb2-SOS complex in insulin receptor signaling. J. Cell. Biochem. 2002, 86, 99-106.

38. Trub, T.; Frantz, J.D.; Miyazaki, M.; Band, H.; Shoelson, S.E. The role of a lymphoid-restricted, Grb2-Like SH3-SH2-SH3 protein in T cell receptor signaling. J. Biol. Chem. 1997, 272, 894-902.

39. Lawe, D.C.; Hahn, C.; Wong, A.J. The Nck SH2/SH3 adaptor protein is present in the nucleus and associates with the nuclear protein SAM68. Oncogene 1997, 14, 223-231.

40. Locatelli, A.; Lange, C.A. Met receptors induce Sam68-dependent cell migration by activation of alternate extracellular signal-regulated kinase family members. J. Biol. Chem. 2011, 286, 21062-21072.

41. Derry, J.J.; Richard, S.; Valderrama Carvajal, H.; Ye, X.; Vasioukhin, V.; Cochrane, A.W.; Chen, T.; Tyner, A.L. Sik (BRK) phosphorylates Sam68 in the nucleus and negatively regulates its RNA binding ability. Mol. Cell. Biol. 2000, 20, 6114-6126.

42. Chen, Z.Y.; Cai, L.; Zhu, J.; Chen, M.; Chen, J.; Li, Z.H.; Liu, X.D.; Wang, S.G.; Bie, P.; Jiang, P.; et al. Fyn requires HnRNPA2B1 and Sam68 to synergistically regulate apoptosis in pancreatic cancer. Carcinogenesis 2011, 32, 1419-1426. 
43. Fusaki, N.; Iwamatsu, A.; Iwashima, M.; Fujisawa, J. Interaction between Sam68 and Src family tyrosine kinases, Fyn and Lck, in T cell receptor signaling. J. Biol. Chem. 1997, 272, 6214-6219.

44. Lang, V.; Mege, D.; Semichon, M.; Gary-Gouy, H.; Bismuth, G. A dual participation of ZAP-70 and Scr protein tyrosine kinases is required for TCR-induced tyrosine phosphorylation of Sam68 in Jurkat T cells. Eur. J. Immunol. 1997, 27, 3360-3367.

45. Sanchez-Margalet, V.; Najib, S. P68 Sam is a substrate of the insulin receptor and associates with the SH2 domains of p85 PI3K. FEBS Lett. 1999, 455, 307-310.

46. Guitard, E.; Barlat, I.; Maurier, F.; Schweighoffer, F.; Tocque, B. Sam68 is a Ras-GAP-associated protein in mitosis. Biochem. Biophys. Res. Commun. 1998, 245, 562-566.

47. Sanchez-Margalet, V.; Najib, S. Sam68 is a docking protein linking GAP and PI3K in insulin receptor signaling. Mol. Cell. Endocrinol. 2001, 183, 113-121.

48. Andreotti, A.H.; Bunnell, S.C.; Feng, S.; Berg, L.J.; Schreiber, S.L. Regulatory intramolecular association in a tyrosine kinase of the Tec family. Nature 1997, 385, 93-97.

49. Ramakrishnan, P.; Baltimore, D. Sam68 is required for both NF-kappaB activation and apoptosis signaling by the TNF receptor. Mol. Cell 2011, 43, 167-179.

50. Jabado, N.; Pallier, A.; le Deist, F.; Bernard, F.; Fischer, A.; Hivroz, C. CD4 Ligands inhibit the formation of multifunctional transduction complexes involved in T Cell activation. J. Immunol. 1997, 158, 94-103.

51. Jauliac, S.; Mazerolles, F.; Jabado, N.; Pallier, A.; Bernard, F.; Peake, J.; Fischer, A.; Hivroz, C. Ligands of CD4 inhibit the association of phospholipase cgamma1 with phosphoinositide 3 kinase in T cells: Regulation of this association by the phosphoinositide 3 Kinase activity. Eur. J. Immunol. 1998, 28, 3183-3191.

52. Hawkins, J.; Marcy, A. Characterization of Itk tyrosine kinase: Contribution of noncatalytic domains to enzymatic activity. Protein Expr. Purif. 2001, 22, 211-219.

53. Sanchez-Margalet, V.; Gonzalez-Yanes, C.; Najib, S.; Fernandez-Santos, J.M.; Martin-Lacave, I. The expression of Sam68, a protein involved in insulin signal transduction, is enhanced by insulin stimulation. Cell Mol. Life Sci. 2003, 60, 751-758.

54. Sanchez-Margalet, V.; Martin-Romero, C.; Santos-Alvarez, J.; Goberna, R.; Najib, S.; Gonzalez-Yanes, C. Role of leptin as an immunomodulator of blood mononuclear cells: Mechanisms of action. Clin. Exp. Immunol. 2003, 133, 11-19.

55. Martin-Romero, C.; Sanchez-Margalet, V. Human leptin activates PI3K and MAPK pathways in human peripheral blood mononuclear cells: Possible role of Sam68. Cell. Immunol. 2001, 212, 83-91.

56. Sanchez-Margalet, V.; Martin-Romero, C. Human leptin signaling in human peripheral blood mononuclear cells: Activation of the JAK-STAT pathway. Cell. Immunol. 2001, 211, 30-36.

57. Sanchez-Jimenez, F.; Perez-Perez, A.; Gonzalez-Yanes, C.; Najib, S.; Varone, C.L.; Sanchez-Margalet, V. Leptin receptor activation increases Sam68 tyrosine phosphorylation and expression in human trophoblastic cells. Mol. Cell. Endocrinol. 2011, 332, 221-227.

58. Kunkel, G.T.; Wang, X. Sam68 guest STARs in TNF-alpha signaling. Mol. Cell 2011, 43, 157-158.

59. Lukong, K.E.; Larocque, D.; Tyner, A.L.; Richard, S. Tyrosine phosphorylation of sam68 by breast tumor kinase regulates intranuclear localization and cell cycle progression. J. Biol. Chem. 2005, 280, 38639-38647. 
60. Locatelli, A.; Lofgren, K.A.; Daniel, A.R.; Castro, N.E.; Lange, C.A. Mechanisms of HGF/Met signaling to Brk and Sam68 in breast cancer progression. Horm. Cancer 2012, 3, 14-25.

61. Venigalla, R.K.; Turner, M. RNA-binding proteins as a point of convergence of the PI3K and p38 MAPK pathways. Front. Immunol. 2012, 3, 398.

62. Sanchez-Jimenez, F.; Perez-Perez, A.; Gonzalez-Yanes, C.; Varone, C.L.; Sanchez-Margalet, V. Sam68 mediates leptin-stimulated growth by modulating leptin receptor signaling in human trophoblastic JEG-3 cells. Hum. Reprod. 2011, 26, 2306-2315.

63. Najib, S.; Martin-Romero, C.; Gonzalez-Yanes, C.; Sanchez-Margalet, V. Role of Sam68 as an adaptor protein in signal transduction. Cell Mol. Life Sci. 2005, 62, 36-43.

64. Lukong, K.E.; Richard, S. Targeting the RNA-binding protein Sam68 as a treatment for cancer? Future Oncol. 2007, 3, 539-544.

65. Liu, K.; Li, L.; Nisson, P.E.; Gruber, C.; Jessee, J.; Cohen, S.N. Neoplastic transformation and tumorigenesis associated with sam68 protein deficiency in cultured murine fibroblasts. J. Biol. Chem. 2000, 275, 40195-40201.

66. Taylor, S.J.; Resnick, R.J.; Shalloway, D. Sam68 exerts separable effects on cell cycle progression and apoptosis. BMC Cell Biol. 2004, 5, 5.

67. Paronetto, M.P.; Farini, D.; Sammarco, I.; Maturo, G.; Vespasiani, G.; Geremia, R.; Rossi, P.; Sette, C. Expression of a truncated form of the c-Kit tyrosine kinase receptor and activation of Src kinase in human prostatic cancer. Am. J. Pathol. 2004, 164, 1243-1251.

68. Busa, R.; Paronetto, M.P.; Farini, D.; Pierantozzi, E.; Botti, F.; Angelini, D.F.; Attisani, F.; Vespasiani, G.; Sette, C. The RNA-binding protein Sam68 contributes to proliferation and survival of human prostate cancer cells. Oncogene 2007, 26, 4372-4382.

69. Richard, S.; Vogel, G.; Huot, M.E.; Guo, T.; Muller, W.J.; Lukong, K.E. Sam68 haploinsufficiency delays onset of mammary tumorigenesis and metastasis. Oncogene 2008, 27, 548-556.

70. Bielli, P.; Busa, R.; Paronetto, M.P.; Sette, C. The RNA-binding protein Sam68 is a multifunctional player in human cancer. Endocr. Relat. Cancer 2011, 18, R91-R102.

71. Li, Z.; Yu, C.P.; Zhong, Y.; Liu, T.J.; Huang, Q.D.; Zhao, X.H.; Huang, H.; Tu, H.; Jiang, S.; Zhang, Y.; et al. Sam68 expression and cytoplasmic localization is correlated with lymph node metastasis as well as prognosis in patients with early-stage cervical cancer. Ann. Oncol. 2012, 23, 638-646.

72. Chen, S.W.; Zhang, Q.; Yang, A.K.; Li, Z.; Zhong, Y.; Li, H.; Zeng, Y.; Zhuang, S.M.; Wang, L.P.; Song, L.B.; et al. Overexpression and cytoplasmic localization of Sam68 correlate with tumour progression and poor prognosis in patients with clinically N0 oral tongue cancer. Head. Neck. Oncol. 2012, 4, 61.

73. Liao, W.T.; Liu, J.L.; Wang, Z.G.; Cui, Y.M.; Shi, L.; Li, T.T.; Zhao, X.H.; Chen, X.T.; Ding, Y.Q.; Song, L.B. High expression level and nuclear localization of Sam68 are associated with progression and poor prognosis in colorectal cancer. BMC Gastroenterol. 2013, 13, 126.

74. Richard, S.; Torabi, N.; Franco, G.V.; Tremblay, G.A.; Chen, T.; Vogel, G.; Morel, M.; Cleroux, P.; Forget-Richard, A.; Komarova, S.; et al. Ablation of the Sam68 RNA binding protein protects mice from age-related bone loss. PLoS Genet. 2005, 1, e74. 
75. Bianchi, E.; Barbagallo, F.; Valeri, C.; Geremia, R.; Salustri, A.; de Felici, M.; Sette, C. Ablation of the Sam68 gene impairs female fertility and gonadotropin-dependent follicle development. Hum. Mol. Genet. 2010, 19, 4886-4894.

76. Paronetto, M.P.; Messina, V.; Bianchi, E.; Barchi, M.; Vogel, G.; Moretti, C.; Palombi, F.; Stefanini, M.; Geremia, R.; Richard, S.; et al. Sam68 regulates translation of target mRNAs in male germ cells, necessary for mouse spermatogenesis. J. Cell Biol. 2009, 185, 235-249.

77. Lukong, K.E.; Richard, S. Motor coordination defects in mice deficient for the Sam68 RNA-binding protein. Behav. Brain Res. 2008, 189, 357-363.

78. Huot, M.E.; Vogel, G.; Zabarauskas, A.; Ngo, C.T.; Coulombe-Huntington, J.; Majewski, J.; Richard, S. The Sam68 STAR RNA-binding protein regulates mTOR alternative splicing during adipogenesis. Mol. Cell 2012, 46, 187-199.

79. Yang, J.P.; Reddy, T.R.; Truong, K.T.; Suhasini, M.; Wong-Staal, F. Functional interaction of Sam68 and heterogeneous nuclear ribonucleoprotein K. Oncogene 2002, 21, 7187-7194.

80. Paronetto, M.P.; Achsel, T.; Massiello, A.; Chalfant, C.E.; Sette, C. The RNA-binding protein Sam68 modulates the alternative splicing of Bcl-x. J. Cell Biol. 2007, 176, 929-939.

81. Ulke-Lemee, A.; Trinkle-Mulcahy, L.; Chaulk, S.; Bernstein, N.K.; Morrice, N.; Glover, M.; Lamond, A.I.; Moorhead, G.B. The nuclear PP1 interacting protein ZAP3 (ZAP) is a putative nucleoside kinase that complexes with SAM68, CIA, NF110/45, and HNRNP-G. Biochim. Biophys. Acta 2007, 1774, 1339-1350.

82. Simarro, M.; Mauger, D.; Rhee, K.; Pujana, M.A.; Kedersha, N.L.; Yamasaki, S.; Cusick, M.E.; Vidal, M.; Garcia-Blanco, M.A.; Anderson, P. Fas-activated serine/threonine phosphoprotein (FAST) is a regulator of alternative splicing. Proc. Natl. Acad. Sci. USA 2007, 104, 11370-11375.

83. Kim, H.J.; Kim, N.C.; Wang, Y.D.; Scarborough, E.A.; Moore, J.; Diaz, Z.; MacLea, K.S.; Freibaum, B.; Li, S.; Molliex, A.; et al. Mutations in prion-like domains in hnRNPA2B1 and hnRNPA1 cause multisystem proteinopathy and ALS. Nature 2013, 495, 467-473.

84. Berson, A.; Barbash, S.; Shaltiel, G.; Goll, Y.; Hanin, G.; Greenberg, D.S.; Ketzef, M.; Becker, A.J.; Friedman, A.; Soreq, H. Cholinergic-associated loss of hnRNP-A/B in Alzheimer's disease impairs cortical splicing and cognitive function in mice. EMBO Mol. Med. 2012, 4, 730-742.

85. Chen, T.; Boisvert, F.M.; Bazett-Jones, D.P.; Richard, S. A role for the GSG domain in localizing Sam68 to novel nuclear structures in cancer cell lines. Mol. Biol. Cell 1999, 10, 3015-3033.

86. Huot, M.E.; Vogel, G.; Richard, S. Identification of a Sam68 ribonucleoprotein complex regulated by epidermal growth factor. J. Biol. Chem. 2009, 284, 31903-31913.

87. Hartmann, A.M.; Nayler, O.; Schwaiger, F.W.; Obermeier, A.; Stamm, S. The interaction and colocalization of Sam68 with the splicing-associated factor YT521-B in nuclear dots is regulated by the Src family kinase p59(Fyn). Mol. Biol. Cell 1999, 10, 3909-3926.

88. Rajan, P.; Dalgliesh, C.; Bourgeois, C.F.; Heiner, M.; Emami, K.; Clark, E.L.; Bindereif, A.; Stevenin, J.; Robson, C.N.; Leung, H.Y.; et al. Proteomic identification of heterogeneous nuclear ribonucleoprotein L as a novel component of SLM/Sam68 nuclear bodies. BMC Cell Biol. 2009, 10,82 . 
89. Biamonti, G.; Caceres, J.F. Cellular stress and RNA splicing. Trends Biochem. Sci. 2009, 34, 146-153.

90. Biamonti, G. Nuclear stress bodies: A heterochromatin affair? Nat. Rev. Mol. Cell Biol. 2004, 5, 493-498.

91. Denegri, M.; Chiodi, I.; Corioni, M.; Cobianchi, F.; Riva, S.; Biamonti, G. Stress-induced nuclear bodies are sites of accumulation of Pre-mRNA processing factors. Mol. Biol. Cell 2001, 12, 3502-3514.

92. Busa, R.; Geremia, R.; Sette, C. Genotoxic stress causes the accumulation of the splicing regulator Sam68 in nuclear foci of transcriptionally active chromatin. Nucleic Acids Res. 2010, 38, 3005-3018.

93. Anderson, P.; Kedersha, N. RNA granules: Post-transcriptional and epigenetic modulators of gene expression. Nat. Rev. Mol. Cell Biol. 2009, 10, 430-436.

94. Henao-Mejia, J.; He, J.J. Sam68 relocalization into stress granules in response to oxidative stress through complexing with TIA-1. Exp. Cell Res. 2009, 315, 3381-3395.

95. Piotrowska, J.; Hansen, S.J.; Park, N.; Jamka, K.; Sarnow, P.; Gustin, K.E. Stable formation of compositionally unique stress granules in virus-infected cells. J. Virol. 2010, 84, 3654-3665.

96. Finnen, R.L.; Pangka, K.R.; Banfield, B.W. Herpes simplex Virus 2 infection impacts stress granule accumulation. J. Virol. 2012, 86, 8119-8130.

97. Messina, V.; Meikar, O.; Paronetto, M.P.; Calabretta, S.; Geremia, R.; Kotaja, N.; Sette, C. The RNA binding protein SAM68 transiently localizes in the chromatoid body of male germ cells and influences expression of select microRNAs. PLoS One 2012, 7, e39729.

98. Lynch, K.W. Regulation of alternative splicing by signal transduction pathways. Adv. Exp. Med. Biol. 2007, 623, 161-174.

99. Grossman, J.S.; Meyer, M.I.; Wang, Y.C.; Mulligan, G.J.; Kobayashi, R.; Helfman, D.M. The use of antibodies to the Polypyrimidine Tract Binding protein (PTB) to analyze the protein components that assemble on alternatively spliced pre-mRNAs that use distant branch points. RNA 1998, 4, 613-625.

100. Chawla, G.; Lin, C.H.; Han, A.; Shiue, L.; Ares, M., Jr.; Black, D.L. Sam68 regulates a set of alternatively spliced exons during neurogenesis. Mol. Cell. Biol. 2009, 29, 201-213.

101. Stoss, O.; Novoyatleva, T.; Gencheva, M.; Olbrich, M.; Benderska, N.; Stamm, S. P59(Fyn)-mediated phosphorylation regulates the activity of the tissue-specific splicing factor rSLM-1. Mol. Cell. Neurosci. 2004, 27, 8-21.

102. Song, L.; Wang, L.; Li, Y.; Xiong, H.; Wu, J.; Li, J.; Li, M. Sam68 up-regulation correlates with, and its down-regulation inhibits, proliferation and tumourigenicity of breast cancer cells. J. Pathol. 2010, 222, 227-237.

103. Rajan, P.; Gaughan, L.; Dalgliesh, C.; El-Sherif, A.; Robson, C.N.; Leung, H.Y.; Elliott, D.J. The RNA-binding and adaptor protein Sam68 modulates signal-dependent splicing and transcriptional activity of the androgen receptor. J. Pathol. 2008, 215, 67-77.

104. Zhang, Z.; Li, J.; Zheng, H.; Yu, C.; Chen, J.; Liu, Z.; Li, M.; Zeng, M.; Zhou, F.; Song, L. Expression and cytoplasmic localization of SAM68 is a significant and independent prognostic marker for renal cell carcinoma. Cancer Epidemiol. Biomark. Prev. 2009, 18, 2685-2693. 
105. Naor, D.; Nedvetzki, S.; Golan, I.; Melnik, L.; Faitelson, Y. CD44 in cancer. Crit. Rev. Clin. Lab. Sci. 2002, 39, 527-579.

106. Cheng, C.; Sharp, P.A. Regulation of CD44 alternative splicing by SRm160 and its potential role in tumor cell invasion. Mol. Cell. Biol. 2006, 26, 362-370.

107. Batsche, E.; Yaniv, M.; Muchardt, C. The human SWI/SNF subunit Brm is a regulator of alternative splicing. Nat. Struct. Mol. Biol. 2006, 13, 22-29.

108. Cappellari, M.; Bielli, P.; Paronetto, M.P.; Ciccosanti, F.; Fimia, G.M.; Saarikettu, J.; Silvennoinen, O.; Sette, C. The transcriptional co-activator SND1 is a novel regulator of alternative splicing in prostate cancer cells. Oncogene 2013, doi:10.1038/onc.2013.360.

109. Rosenberger, S.; De-Castro Arce, J.; Langbein, L.; Steenbergen, R.D.; Rosl, F. Alternative splicing of human papillomavirus type-16 E6/E6* early mRNA is coupled to EGF signaling via Erk1/2 activation. Proc. Natl. Acad. Sci. USA 2010, 107, 7006-7011.

110. Tisserant, A.; Konig, H. Signal-regulated pre-mRNA occupancy by the general splicing factor U2AF. PLoS One 2008, 3, e1418.

111. Valacca, C.; Bonomi, S.; Buratti, E.; Pedrotti, S.; Baralle, F.E.; Sette, C.; Ghigna, C.; Biamonti, G. Sam68 regulates EMT through alternative splicing-activated nonsense-mediated mRNA decay of the SF2/ASF proto-oncogene. J. Cell Biol. 2010, 191, 87-99.

112. Paronetto, M.P.; Cappellari, M.; Busa, R.; Pedrotti, S.; Vitali, R.; Comstock, C.; Hyslop, T.; Knudsen, K.E.; Sette, C. Alternative splicing of the cyclin D1 proto-oncogene is regulated by the RNA-binding protein Sam68. Cancer Res. 2010, 70, 229-239.

113. Morishita, E.C.; Murayama, K.; Kato-Murayama, M.; Ishizuka-Katsura, Y.; Tomabechi, Y.; Hayashi, T.; Terada, T.; Handa, N.; Shirouzu, M.; Akiyama, T.; et al. Crystal structures of the armadillo repeat domain of adenomatous polyposis coli and its complex with the tyrosine-rich domain of Sam68. Structure 2011, 19, 1496-1508.

114. Paronetto, M.P.; Messina, V.; Barchi, M.; Geremia, R.; Richard, S.; Sette, C. Sam68 marks the transcriptionally active stages of spermatogenesis and modulates alternative splicing in male germ cells. Nucleic Acids Res. 2011, 39, 4961-4974.

115. Tassone, F.; Hagerman, R. The fragile X-associated tremor ataxia syndrome. Results Probl. Cell Differ. 2012, 54, 337-357.

116. Iijima, T.; Wu, K.; Witte, H.; Hanno-Iijima, Y.; Glatter, T.; Richard, S.; Scheiffele, P. SAM68 regulates neuronal activity-dependent alternative splicing of neurexin-1. Cell 2011, 147, 1601-1614.

117. Sellier, C.; Rau, F.; Liu, Y.; Tassone, F.; Hukema, R.K.; Gattoni, R.; Schneider, A.; Richard, S.; Willemsen, R.; Elliott, D.J.; et al. Sam68 sequestration and partial loss of function are associated with splicing alterations in FXTAS patients. EMBO J. 2010, 29, 1248-1261.

118. Pedrotti, S.; Bielli, P.; Paronetto, M.P.; Ciccosanti, F.; Fimia, G.M.; Stamm, S.; Manley, J.L.; Sette, C. The splicing regulator Sam68 binds to a novel exonic splicing silencer and functions in SMN2 alternative splicing in spinal muscular atrophy. EMBO J. 2010, 29, 1235-1247.

119. Pedrotti, S.; Sette, C. Spinal muscular atrophy: A new player joins the battle for SMN2 Exon 7 splicing. Cell Cycle 2010, 9, 3874-3879. 
120. Hong, W.; Resnick, R.J.; Rakowski, C.; Shalloway, D.; Taylor, S.J.; Blobel, G.A. Physical and functional interaction between the transcriptional cofactor $\mathrm{CBP}$ and the $\mathrm{KH}$ domain protein Sam68. Mol. Cancer Res. 2002, 1, 48-55.

121. Auboeuf, D.; Dowhan, D.H.; Dutertre, M.; Martin, N.; Berget, S.M.; O’Malley, B.W. A subset of nuclear receptor coregulators act as coupling proteins during synthesis and maturation of RNA transcripts. Mol. Cell Biol. 2005, 25, 5307-5316.

122. Sette, C. Post-translational regulation of star proteins and effects on their biological functions. Adv. Exp. Med. Biol. 2010, 693, 54-66.

123. Subramanyam, D.; Blelloch, R. From microRNAs to targets: Pathway discovery in cell fate transitions. Curr. Opin. Genet. Dev. 2011, 21, 498-503.

124. Porkka, K.P.; Pfeiffer, M.J.; Waltering, K.K.; Vessella, R.L.; Tammela, T.L.; Visakorpi, T. MicroRNA expression profiling in prostate cancer. Cancer Res. 2007, 67, 6130-6135.

125. Ru, P.; Steele, R.; Newhall, P.; Phillips, N.J.; Toth, K.; Ray, R.B. miRNA-29b suppresses prostate cancer metastasis by regulating epithelial-mesenchymal transition signaling. Mol. Cancer. Ther. 2012, 11, 1166-1173.

126. Suhasini, M.; Reddy, T.R. Cellular proteins and HIV-1 Rev function. Curr. HIV Res. 2009, 7 , 91-100.

127. Reddy, T.R.; Xu, W.; Mau, J.K.; Goodwin, C.D.; Suhasini, M.; Tang, H.; Frimpong, K.; Rose, D.W.; Wong-Staal, F. Inhibition of HIV replication by dominant negative mutants of Sam68, a functional homolog of HIV-1. Rev. Nat. Med. 1999, 5, 635-642.

128. Soros, V.B.; Carvajal, H.V.; Richard, S.; Cochrane, A.W. Inhibition of human immunodeficiency virus type $1 \mathrm{Rev}$ function by a dominant-negative mutant of Sam68 through sequestration of unspliced RNA at perinuclear bundles. J. Virol. 2001, 75, 8203-8215.

129. Modem, S.; Badri, K.R.; Holland, T.C.; Reddy, T.R. Sam68 is absolutely required for Rev function and HIV-1 production. Nucleic Acids Res. 2005, 33, 873-879.

130. Klein, M.E.; Younts, T.J.; Castillo, P.E.; Jordan, B.A. RNA-binding protein Sam68 controls synapse number and local beta-actin mRNA metabolism in dendrites. Proc. Natl. Acad. Sci. USA 2013, 110, 3125-3130.

(C) 2013 by the authors; licensee MDPI, Basel, Switzerland. This article is an open access article distributed under the terms and conditions of the Creative Commons Attribution license (http://creativecommons.org/licenses/by/3.0/). 